\title{
Infectious diseases and the anaesthetist
}

Anaesthetists are sometimes confronted with a patient who has a known transmissible disease and special care has to be observed. However, there are many patients who may be carriers of an infectious diseuse which hus not been diagnosed. In view of this it is best to consider that all patients are potentially infectious. This is also the recent recommendation of the Centers for Disease Control (CDC) in Atlanta, Georgia.' These recommendations emphasize the need to treat blood and other body fluids from all patients as potentially infective. The wisdom of this action is confirmed by the study of Handsfield $e t a l^{2}$ in which they sought to document the incidence of hepatitis B virus (HBV) and the AIDS virus (HIV) in blood samples submitted to the chemistry laboratory of an urban teaching hospital. A total of 506 specimens was examined. Forty-four samples ( 8.7 per cent) had one or both vinuses present.

Three aspects are to be discussed:

1 Prevention of infections transferred from patient to patient.

2 Prevention of infections between patients and staff.

3 More common infectious diseases which may be cncountered in the operating room

\section{Prevention of infections transterred from patient to patient}

The best method of preventing spread of disease from patient to patient is by the use of sterile disposable equipment. In addition, at the end of each operation, the operating room must be cleaned by mopping the floor and any contaminated areas with a germicidal detergent. However, for economical reasons in centres where large numbers of anaesthetics are given, it may be elected to reuse certain items of equipment which have to be either resterilized or subjected to high level disinfection before use again. Items or devices that cannot be cleaned and sterilized or disinfected without altering their physical integrity and function should not be reprocessed. Satisfac-

From the Departments of Anaesthesia, Paediatrics and Pathology, Faculty of Health Sciences, MeMaster University, Hamilton, Ontario.

Address correspondence to: Dr. Ronald A. Browne, Department of Anaesthesia, Hamilton General Hospital, 237 Barton Street East, Hamilton, Ontario L8L 2 X2. tory methods of achieving disinfection and sterilization are summarized in Table $I$, which illustrates that there are usually altemative methods of dealing with each item of equipment. Infection may be possible if the same anaesthetic equipment (unsterilized) is used for more than one patient. Critical items are instruments or objects that are introduced directly into the bloodstream or into other normally sterile areas of the body. Examples are needles, cannulae and central venous and Swan Ganz catheters. Sterility at the time of use is required for these items.

Other items such as non-invasive endoscopes, endotracheal tubes and anaesthetic circuits, may contact intact mucous membranes, but do not usually penetrate bady surfaces. These should be disposable or treated by disinfection, a procedure which will destroy vegetative micro-organisms, tubercle bacilli (TB), viruses and fungi. ${ }^{3}$ This process is described later in this report.

Items which do not touch the patient or touch only intact skin, do not normally transmit disease. These may be treated by washing with a detergent. Examples are blood pressure cuffs, stethoscopes and oxineter probes. These methods have been described by the $\mathrm{CDC}^{4}{ }^{4}$

Items for disposal should be placed in a yellow plastic garbage bag which is sent for incineration. Plastic endotracheal tubes are usually treated in this manner. In Canada, the colour ycllow indicates that it is destined for incineration.

Steam sterilization at $132^{\circ} \mathrm{C}$ for ten minutes is the method of choice for items which can withstand high temperarures. Examples are laryngoscope blades and heat-resistant anaesthetic valves, such as the valves used with the Bain and Penlon circuits.

Some items may be dealt with by high level disinfection. This is suitable for plastic tubing and rubber goods such as bags and face masks, which will not withstand the high temperatures involved in steam sterilization. The Pasteuramatic process is an example of this in which the items are placed in a machine which subjects them to a 30-minute wash cycle, followed by a cycle in which they are exposed to hot water at a temperature of $77^{\circ} \mathrm{C}$ for 30 minutes. This method will kill all pathogenic organisms except resistant spores. All of the Gram-negative organisms which tend to accumulate in moist anaesthetic circuits will be killed, ${ }^{5}$ as well as all viruses and fungi. As an alternative some items may be immersed in chemical germicides, such as two per cent active glutaraldehyde 
TABLE I Methods of treating anaesthetic equipment

\begin{tabular}{|c|c|}
\hline Method of ireatment & Equipment item \\
\hline Disposed of by incineration & $\begin{array}{l}\text { - Plastic endotracheal tubes (usual meihod) } \\
\text { - Airways } \\
\text { - Needles } \\
\text { - Intravenous fuids } \\
\text { - Catheters Epidural } \\
\text { - Urinary containers } \\
\text { - Anacsthesia circuit tubing } \\
\text { - Syringes } \\
\text { - Intravcnous scts } \\
\text { - Nasogastric tubes }\end{array}$ \\
\hline Pas:eurmatic process or chemical disinfection & $\begin{array}{l}\text { - Anacsthetic circuit tubing } \\
\text { - Rubber bags } \\
\text { - Airways } \\
\text { - Face masks }\end{array}$ \\
\hline Steam sterilization $\left(132^{\circ} \mathrm{C}-10\right.$ minutes $)$ & $\begin{array}{l}\text { - Anaesthetic valves, such as Bain and Penlon circuit valves } \\
\text { - Laryngoscope blades }\end{array}$ \\
\hline Ethylene oxide sterilization & $\begin{array}{l}\text { - Anacsthetic circuit tubing } \\
\text { - Ventilator bellows } \\
\text { - Airways } \\
\text { - Soda lime cannisters } \\
\text { - Flexible fiberoptic lafyngoscopes and bronchoscopes }\end{array}$ \\
\hline
\end{tabular}

(Sporicidin ${ }^{2}$ ) for 45 minutes or two per cent final concentration of ordinary glutaraldehyde for ten hours (Cidex ${ }^{(3)}$. They must be rinsed with sterile water before reuse. Ethylene oxide sterilization is useful for items which are thernolabile. Included in this group are anaesthetic circuit tubing and ventilator bellows. The main disadvantage is the length of time required for the sterilization plus aeration process. If this method is used, this will necessitate having to keep a large stock of equipenent.

Bacterial filtres may be used to protect complex, difficult-to-sterilize equipment such as ventilators and soda lime absorbers from bacterial and viral contamination. ${ }^{6,7}$ While it is accepted that these filtres $(0.2$ micron pore size) are 99.99 per cent efficient for the filtration of bacteria, there is still some contention as to their adequacy in removing viruses. Recent studies seem to indicate that they are also efficient in removing viruses. 8,9 The physical mechanisms by which particles are captured are said to be by direct interception, inertial impaction and diffusional interception. ${ }^{10}$ There are many different types of pollution control systems in use. However, they are not important as a possible source for passing on infection either from patient to patient or from patient to staff. These systems collect excess gases from the anaesthetic circuits and ventilators. The gases are then exhausted to the outside, usually via the exhaust duct of the ventilation system or by low pressure suction. A satisfactory method of treating these is to wash the scavenging device in a detergent solution monthly and to change the plastic hoses which connect the device to the anaesthetic circuit and ventilator at the same time.

\section{Prevention of infections between patients and staff}

The high-risk patient

Patients whom we consider to be a high risk for passing on infection should be managed with caution and investigated preoperatively as far as possible to elucidate their infectivity. By far the two most serious conditions in North America which we may contact are infections with HBV and HIV. The topic of "patient consent" for Anti-HIV testing is still controversial. Some physicians think that every patient who is admitted for surgery should be automatically tested without permission for Anti-HIV. On the other hand, there are those who think that testing without permission should not be undertaken and that permission should be sought only for those individuals in a high-risk group. Hospitals are presently deliberating over this problem.

The following groups have been determined as being at high risk for HIV infection:

1 Homosexual or bisexual men.

2 Intravenous drug abusers.

3 Haemophiliacs or frequent recipients of blood or blood product transfusion.

4 People from endemic areas, such as Central Africa, West Africa and the Carribean. 
5 Sexual partners of patients with HIV infection.

6 Children born to mothers infected with HIV.

\section{Danor blood}

The Red Cross will not accept blood from anyone admitting to a history of previous jaundice or hepatitis, veneral disease, or anyone in what is considered to be a "high-risk" group for infectivity. Donor blood in Canada is screened for hepatitis B antigen (HBsAg), Anti-HIV syphilis, and if for neonates or transplant patients, Cytomegalovirus (CMV). However, the following are important points to note:

a The test for $\mathrm{HBs} \mathrm{Ag}$, although highly sensitive, is not infallible. Five per cent of cases of post-transfusion hepatitis are still due to $\mathrm{HBV},{ }^{11}$ although the donor blood tested negative for $\mathrm{HBs} \mathrm{Ag}$. This is probably due to a level of HBsAg which is too low to be detected by radioimmunoassay.

b There is no test for Non A, Non B Hepatitis (NANBH), which causes 90 per cent of cases of post-transfusion hepatitis. Surrogate (indirect) testing for anti-HBe and Alanineaminotransferase (ALT) has been adopted in the U.S.A. by the American Association of Blood Banks. This is said to reduce the incidence of NANBH cases after transfusion by 40 per cent. ${ }^{12}$ As of 1 st May 1988, this testing has not yet started in Canada. It has also been calculated that this will reduce the number of donors by five per cent. ${ }^{13}$

c The enzyme-linked immunosorbent assay (ELISA) for Anti-HIV is also not infallible. The donor may have been in the early stage of the incubation period when the blood was donated. The test may therefore be negative, but the blood may be infectious. Given that the sensitivity of the ELISA test is not 100 per cent it appears now that the chances of a unit of blood which is positive for the antibody to HIV being transfused in the United States are roughly 1 in $250,000 .^{14}$

During 1987, the Canadian Red Cross Society (CRCS) carried out a pilot study and in January 1988, the formal autologous blond transfusion program was started in Canada. Patients may have their blood withdrawn prcoperatively at the request of their physician. The blond will then be stored in liquid form and the present 35-day self-life will allow for a maximum of four units to be collected. The donations are made at weekly intervals with the last unit being collected one week prior to the surgery. The service is presently offered in Canada only for patients undergoing surgery. It is tested in exactly the same manner as ordinary donor blood. It is rejected if found to be positive for Anti-HIV. If it is found to be positive for $\mathrm{HBsAg}$, then it may still be used if the surgeon agrees and the specimen is flagged. It was estimated in the pilot study in Hamilton, Ontario, which was carried out in
1987, that 40 per cent of the patients would have been ineligible as regular blood donors because of past history. ${ }^{\text {is }}$ Unlike regular blood donors, autologous donors may take medication, may have had hepatitis or malaria, and may have undergone cancer treatment. In Canada, if the blood is not required in the perioperative period, it may be put into the general donor pool if the tests are satisfactory and if the patient agrees. At least one private autologous program has been established in Canada and more may follow. ${ }^{15}$

In view of these facts, therefore, donor blood from all sources must be handled with respect by the anaesthetist, and gloves should be wom. High-risk blood products are multiple ponled donor products, such as platelet packs, fibrinogen and cryoprecipitate. Factor VIII concentrate used by haemophiliacs is now heat-treated, which inactivates HIV and HBV. However, HIV infection may still develop in some individuals infected by this route before 198.5 when testing for Anti-HIV started. Average risk blood products are whole blood, packed red blood cells, single donor platelets and plasma. No-risk blood products are albumin, immune globulin, and hyperimmune globulin which are heat treated to $60^{\circ} \mathrm{C}$ or in which cold ethanol extraction is used.

\section{Preventative measures and action on exposure}

All anaesthetists should be aware of the more common infections with which they may come into contact and need to deal with very carefully.

Contact with the patient's skin or body fluids must be made before infection can be transmitted and the wearing of gloves can prevent this. If there is a cut on the anaesthetist's hands, contact with a patient's herpetic lip or the patient's saliva may result in a herpetic whitlow. . $^{\text {if }}$ This is a painful infection of the finger due to herpes simplex virus. It may be accompanied by lymphangitis and axillary lymphadenitis and lake some weeks to heal in the immunocompetent individual.

The body fluids to which the anaesthetist may be exposed are shown in Table II, along with the common diseases which they may transmit. Contact with all of these should be avoided by wearing gloves which should be readily available and be wom during all manoeuvres in which body fluids may be contacted (tracheal intubation, oro-pharyngeal suction, passage of nasogastric tubes, establishing IV's, blood sampling, diluting donor blood with normal saline, changing urine containers, or contacting a patient's skin lesion). Handwashing should be routinely carried out between patients and after removing gloves. If any blood or body fluids touch the anaesthetist's hands, they should be washed immediately with soap and water.

Normally, the intact skin is a good barricr to organisms. 
TABLE II Body fiuids and the diseases they may transmit

\begin{tabular}{ll}
\hline Body fuid & Disease which may be transmitted \\
\hline Blood & HBV, HIV, Non-A, Non-B Hepatitis, CMV, EBV \\
Seminal fluid & HIV, HBV, CMV \\
Vaginal fluid & HIV, HBV, CMV \\
Saliva \& sputum & HSV, TB, CMV, Respiratory diseases (Table IV) \\
CSF & Encephalopathic organisms (Table IV), HIV \\
Brcast milk & HIV, HBV, CMV \\
Urine & CMV, EBV, HBV \\
Faeces \& intestinal fluid & HAV, gastroenteric diseases (Table IV) \\
\hline
\end{tabular}

HBV = Hepatitis B virus; HIV = Human immunodeficiency virus; CMV = Cytomegalovinus; EBV $=$ Epstein-Barr vins; $\mathbf{T B}=$ Tuberculosis; HAV $=$ Hepatitis A virus; $\mathrm{HSV}=$ Herpes Simplex Type 1 and 2.

The conjunctiva of the eyes and nucous membranes are not good barriers to the entry of organisms. This is illustrated by reports of HBV infection following splashing of blood into the eyes. ${ }^{17}$ Any blood or other body fluid splashed into the eyes or face from the patient should be washed off immediately with water. The use of goggles may afford some protection. The latter is especially important in operations in which droplets of blood or other fluid or bone chips are sprayed into the air, for example during dermabrasions and hip surgery. Care must be exercised with all injections and in the disposal of needles. All patient specimens must be labelled accordingly "Body Fluid Precautions." The CDC recommend that since the medical history and examination cannot reliably identify all patients infected with HIV or other blood-borne pathogens, blood and body fluid precautions should be used consistently for all patients ${ }^{1}$ The operating room must be cleansed afterwards with detergent and 1:10 sodium hypochlorite ( 5.25 per cent bleach solution) which is a very effective agent may be used.

The skin barrier, however, may be breached occasionally by a variety of ways. The most common of these are: I Accidental needlestick.

2 Cuts sustained during the cracking of glass ampoules. Anaesthetists crack multiple ampoules daily duning normal anaesthetic practice. In order to avoid finger cuts, all ampoules should be surrounded by a gauze swab before they are cracked.

3 Skin lesions or injuries to the hands sustained outside the operating room by the anaesthetist.

4 Excessive handwashing with drying and cracking of the skin, due to removal of the natural oils.

Accidental needlesticks are the most important source of injury to the anaesthetist. In order to avoid these and their consequences, a strict protocol should be developed and followed. This may include the following:

a All needles which may be reused and which have entered the patient or have been ussed to inject into an intravenous site connceted to a patient should be considered potentially infectious and should not be recapped. This means developing a system for safely keeping syringes with needles attached. This may take the form of placing them in a sterile dish or between two sterile towels. Every anaesthetist should devise a system with which he/she can work comfortably. Alternatively, a fresh syringe and needle can be used for each injection, after which it is immediately discarded.

b Needles should not be bent or broken off from the hub.

c Needles should not be detached from the syringe - use only disposable syringes and discard with needle attached into a suitable container.

d Syringes with needles attached should not be kept in pockets.

e Dispose of all needles and syringes in rigid-walled, puncture-resistant containers placed as close as possible to the area in which the "sharps" are used. This container will also be used to dispose of discarded broken glass ampoules. When this container is threequarters full, it should be capped and sent for disposal by incineration.

A protocol for parenteral or mucous membrane exposures should be devised similar to that illustrated in Table III. In Canada, the Department of National Health and Welfare is conducting a follow-up study of all health care workers exposed to HIV (by needlestick, by contamination of an open wound, splashes in the eyes, or by ingestion). ${ }^{18}$ All such incidents occurring during the management of a patient with HIV infection should be reported to the employee's health service who can obtain an exposure report form from The Laboratory Centre for Disease Control, Ottawa, Ontario K1A 0L2. As of Augusı 1, 1987, 120 health care workers had bcen included in the study. No seroconversion to Anti-HIV positive had occurred up to the date of reporting. Similar ongoing studies are being carried out in the U.S.A. As of March 15, 1988, a study at the University of California of 235 health care workers identified one seroconversion to 
TABLE I1l A protocol for parenteral or mucous membrane exposure to paticnts's body fluids

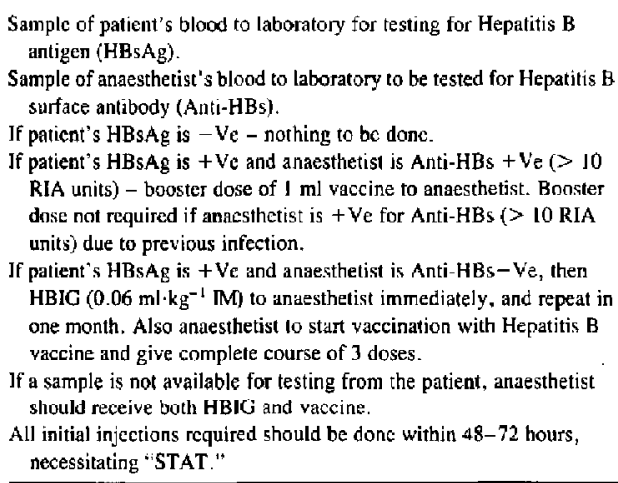

Anti-HIV positive in an individual who sustaincd a ncedlestick. ${ }^{19}$ A study in the United Kingdom showed no evidence of HIV transmission among health care workers with parenteral, mucous membrane or cutaneous exposures. ${ }^{20}$ These studies are consistent with previous observations that the occupational risk of acquiring HIV in the health care setting is low and is most often associated with percutaneous inoculation of blood from a patient with HIV infection. ${ }^{19}$

\section{Infectious diseases which may be encountered in the operating room}

Table IV summarizes infectious diseases which may be contacted in the operating room

The most recent statistics recorded on some of these diseases in Canada and the U.S.A. are shown in Table V.

\section{Viral heparitis}

Hepatitis occurring many years in the past would suggest that it was due to Hepatitis A (HAV). Putients infected in the past with HAV will not spread it in future. However, if hepatitis occurred within the past six to ten years, then other causes would have to be considered. A history of intravenous drug exposure would be important. Blood transfusion in the past prior to testing for HBV hepatitis would suggest either NANBH or HBV infection and testing for HBV may help in this case. Other possibilities, though remote, are CMV and Epstein-Barr Virus (EBV). A history of a general anaesthetic two to three weeks prior to the hepatitis may be significant as being contributory. Whatever the cause of the hepatitis, the anaesthetist should apply "universal body fluid precautions" as suggested by the CDC, ${ }^{1}$ since at the time of surgery the cause of the previous hepatitis will not usually be known
TABLE IV Infectious agents which may be encountered in the operating room

Viral hepatitis

- Hepatitis A vins

- Hepatitis B virus

- Delta Heparitis virus

- Non-A. Non-B Hepatitis viruses

- Human immunodeficicncy virus

- Cytnmegalovinus (CMV)

- Epstein-Bar virus (EBV)

- Herpes Simplex virus viruses (HSV and 2)

- Respiratony bacteria:

- Streptococcal

- Pneumococcal

- Meningacoccal

- Diphtheria

- Mycobacteria*, legionella**

- Fungi

- Candida*

- Nocardia*

- Cryprococcus*

- Parasites

- Pneumoncystis*

- Viruses

- Rhinovirus

- Influenza, parainfluenza

- Adenovirus

- Respiralory syncytial virus

- Measles

- Rubella

- CMV*

$$
\begin{aligned}
& \text { Gastrointestinal (GI) } \\
& \text { - Viruses } \\
& \text { - HAV } \\
& \text { - Rotavinus, adenoviris, enterovitus } \\
& \text { - Bacteria } \\
& \text { - Giardia*, cryptosporidium, sospora* } \\
& \text { - Fungi } \\
& \text { - Candida* } \\
& \text { Centrai nervous system } \\
& \text { - Vinuses } \\
& \text { - HIV* < HSV* Polyonia*, EBV* } \\
& \text { - Parasites } \\
& \text { - Toxoplasma* } \\
& \text { - Fungi } \\
& \text { - Cryptocoscus }
\end{aligned}
$$

*oportunistic infections in jmmunocompromised patients especially those with acquired isrante deficiency

Preoperative testing for $\mathrm{HBsAg}$ is only justified if there is u strong suggestive history of previous $\mathrm{HBV}$ infection.

\section{Hepatitis A virus}

Hepatitis A virus (HAV) infection is predominantly found in children but accounts for 20 per cent of cases of viral hepatitis in adults in the U.S.A. and other industrialized countries. ${ }^{21}$ The disease can occur in epidemic or sporad- 
TABLE V Some notifiable infections reported in Canada and U.S.A. Juring 1987

\begin{tabular}{llc}
\hline & \multicolumn{2}{l}{ County } \\
\cline { 2 - 3 } Disease & Canada & U.S.A. \\
\hline Hepatitis A & 976 & 23,660 \\
Hepatitis B & 2,398 & 24,410 \\
Hepatitis other & & \\
$\quad$ (includes Non-A/Non-B) & 108 & 5,755 \\
TB (not necessarily pulmonary) & 2,046 & 22,768 \\
AIDS & 1,793 (a) & $62,740(\mathrm{~b})$ \\
\hline
\end{tabular}

(a) recorded cases since 1979 to June 13, 1988; reported deaths 1006 . (b) reported since 1979 to June 13, 1988; reported deaths 32,151. Received from Dr. Paul Varughese, Laboratory Centre for Disease Control, Communicable Disease Surveillance Depanment, Ottawa.

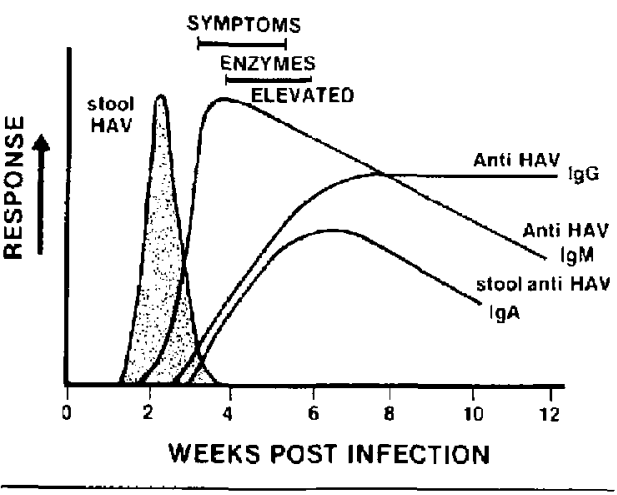

FIGURE I Clinical, serological and biochemical course of typical type A viral hepatitis.

ic form following an incubation period of 15 to 45 days. Figure 1 illustrates the clinical course of the disease.

The diagnosis of Hepatitis $\mathbf{A}$ is made by a history of contact with the discase, either via another case or contaminated food or water. HAV appears to be rarely if ever transmitted by blood transfusion. IgM Anti-HAV is found in the patient's serum in rising titre ${ }^{22}$ The virus is spread typically by the faecal/oral route and about 50 per cent of infections may be asymptomatic. The chronic carrier state is non-existent and chronic hepatitis with cirrhosis is very rare. The disease is usually brief and self-limiting but its importance lies in the fact that the patient may be incubaring it at the time of the anaesthetic. At this time, it is also most infectious. Acute exposure of the anaesthetist to the patient with acute Hepatitis A should result in him/her being given a single dose of gamma glabulin, within two weeks of exposure in a dose of $0.02 \mathrm{ml} \cdot \mathrm{kg}^{-1}$ intramuscularly. This provides a good

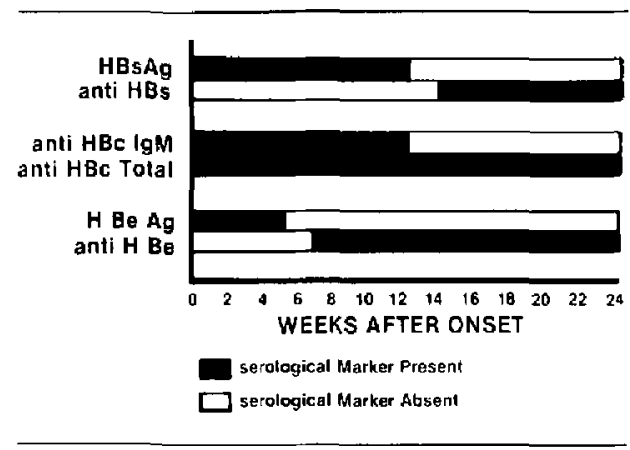

FIGURE 2 Serological markcrs following onset of an acute viral hepatitis $\mathrm{B}$ infection.

degree of protection which lasts for approximately three months. This is a safe product since it is heat and alcohol treated. However, bcfore taking gamma globulin, the anaesthetist should have his/her blood tested for $\operatorname{lgG}$ Anti-HAV. This antibody is present in 30 per cent of North Americans who have had no previous history of hepatitis. ${ }^{23}$ If it is present, the anaesthetist already has immunity to HAV and so does not require gamma globulin which also contains IgG Anti-HAV. The presence of antibody to HAV in the IgG fraction indicates past infection and immunity and this remains for life.

Hepatitis $B$ virus

Several specific markers of Hepatitis $B$ have been described ${ }^{24}$ since the discovery of Hepatitis $B$ antigen (HBsAg) by Blumberg in $1964{ }^{25}$ There are at least three immunologically distinct antigen-antibody systems associated with Hepatitis B virus. In the blood of a patient with acute Hepatitis B or a chronic carrier there can be seen under the electron microscope three types of particles, namely: (1) the Dane particle, $42 \mathrm{~nm}$ in diameter which is the mature virus. This consists of an inner core (containing $\mathrm{HBcAg}$ ) and an outer shell (containing HBsAg); (2) spherical particles $22 \mathrm{~nm}$ in diameter; and (3) long filamentous rods. The latter two consist of HBsAg. The usual sequence of antigenic events that occur in this infection is shown in Figure 2. After a long incubation period of about three months, the acutely infected patient will be antigenaemic (HBsAg positive), and this eventually disappears and is replaced by Anti-HBs. e Antigen is found usually only in HBsAg positive serum and correlates directly with infectivity and the presence of intact viral particles. The presence of Anti-HBe coincides with a period of lower infectivity. Type B Hepatitis, unlike Hepatitis A, shows a tendency to progress to the chronic carrier state in five to ten per cent of cases. ${ }^{26}$ 


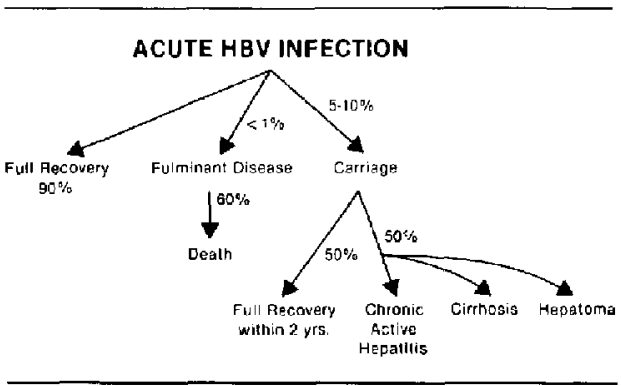

FIGURE 3 The possible sequelae of acute HBV infection.

The possible sequelae of HBV infcction are shown in Figure 3. As indicated there are many possible outcomes, the most favourable being full recovery with reversion to HBsAg negative, and the unfavourable ones being fulminant disease, chronic hepatitis, cirrhosis or the development of hepatoma. Carstens et al ${ }^{27}$ found in a study of 95 South African anaesthetists that 17.9 per cent were positive for Anti-HBs compared with five per cent of the normal population. We have found a similar prevalence of Anti-HBs in a Canadian population of anaesthetists, ${ }^{28}$ indicating the increased exposure risk in this group.

A vaccine is now available which induces active immunity. This may be obtained in two forms:

a Hepatavax which is prepared from the components of the Hepatitis B viral coatings, and does not contain the infectious viral nucleic acid. This has been shown to be safe. ${ }^{29}$ Primary adult vaccination consists of three intramuscular doses of $1 \mathrm{ml}$ of vaccine $(20 \mu \mathrm{g} \mathrm{HBsAg}$ protein each). These are given at 0,1 and 6 months, after which 90 per cent of vaccinated individuals develop adequate protective antibodies (Anti-HBs).

b The second form is the genetically engineered vaccinc ${ }^{30}$ which has recently been developed from brewer's yeast. This is given intramuscularly in doses of $10 \mu \mathrm{g}$ $\mathrm{HBsAg}$ protein $(1 \mathrm{ml})$ each at the same time intervals as the Heptavax. Results are just as good. The anaesthetist should avail himself/herself of one of these vaccines, since the incidence of HBV carriers is 0.5 per cent in the North American population.

A long list of patients who should be routinely tested for HBsAg preoperatively might be constructed. These include patients on haemodialysis, those recently from high prevalence countries, those who have received multiple blood or blood product transfusions, patients with leukaemia or reticuloses, drug addicts, prostitutes and homosexuals, and inmates of mental institutions and prisons. Patients in these groups have a much higher carrier rate for HBV infection than in the general population. Accidental skin puncture in the operating room with contamination of the patient's body fluid should result in the administration of a needlestick protocol (Table III). When dealing with a known carrier of $\mathrm{HBV}$, all barrier precautions should be observed and disposable equipment used as far as possible. The room should be cleaned out with 1.10 bleach solution and the anaesthetic machine washed down.

\section{Delta hepatitis}

The delta agent or hepatitis D virus (HDV) is an RNA virus which coinfects with and reguires the helper function of HBV for its replication and expression. The delta core of the $37 \mathrm{~nm}$ virus is "encapsidated" by an outer coat of HBsAg. Thus, the delta agent can only eithcr infect a person simultaneously with $\mathrm{HBV}$ or superinfect a person already infected with HBV. Because delta relies absolutely on $\mathrm{HBV}$, the duration of delta infection depends on the duration of HBV infection. Antibody to delta agent of the IgM class is produced during acute infection and both IgM and IgG during chronic delta infection. $^{31}$

Studies have also revealed a high prevalence of anti-delta in individuals who have received massive or repeated exposures to blood, blood products or secretions, and in users of illicity parenteral drugs and, to a lesser extent, male homosexuals. ${ }^{32,33}$

Infection with the delta agent follows the same pattern as with Hepatitis $B$ and can thus be prevented by vaccinating susceptible persons with Hepatitis $B$ vaccine. Recently several studies of patients with HBsAg-positive fulminant hepatitis in Europe and the United States have revealed that between a quarter and a half of such cases have evidence of an associated infection with the delta agent. ${ }^{34}$ The delta agent has been demonstrated to be worldwide. Regions with particularly high prevalence of antibody have been found in South America, Africa, the Middle East and Southern Europe. ${ }^{35}$

\section{Non-A, Non-B hepatitis (NANBH)}

Widespread screening of blood donors by sensitive tests have revealed that only five to ten per cent of cases of post-transfusion hepatitis (PTH) are due to HBV. ${ }^{36}$ Testing for Anti-HAV IgM also illustrated the absence of HAV in these cases. As a result, 90 per cent of cases of PTH have therefore been classified as Non- $A$, Non-B Hepatitis. This is therefore a diagnosis by exclusion and depends on the presence of elevated serum transaminases with clinical exclusion of non-viral causes of hepatocellulur injury (i.e., heart failure, drugs) and of HBV, HAV, Cytomegalovirus (CMV) and Epstein-Barr virus (EBV) infections by serological testing. It seems that carriers may be even more common in NANBH than in Hepatitis B, and that NANBH may occur in epidemic form. ${ }^{37}$ It appears that the incubation period may be 2 to 26 weeks, 


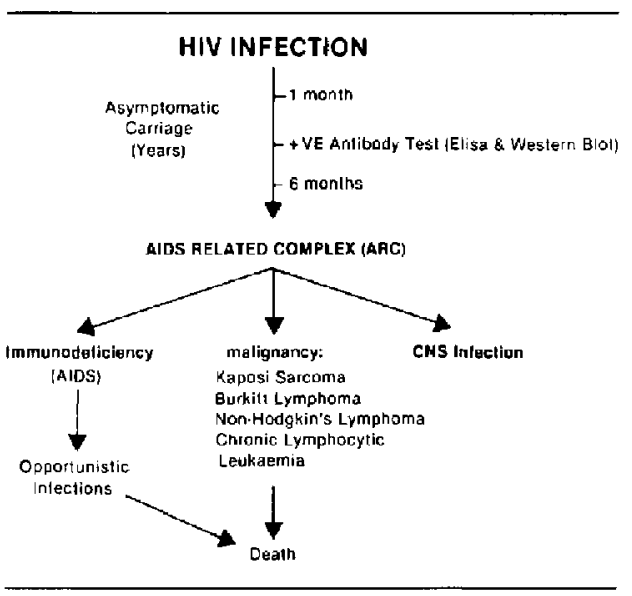

FIGURE 4 Clinical course of HIV infection.

with most cases occurring after transfusion. Less than 25 per cent of cases develop overt icterus. Surrogate testing of blood donors for Anti-HBc and serum ALT and the exclusion of blood which is positive, for either of these may reduce the incidence of NANBH by 40 per cent. ${ }^{13}$

Chronic hepatitis is a frequent sequel of NANBH occurring after transfusion, with abnormal liver function tests persisting for more than a year in 10 to 60 per cent of patients. $^{38}$

Since carriers are common, the anaesthetist must be careful with patients who are in the high-risk group, but who have been found to be negative for HBsAg by testing, since these individuals may still be carriers of NANBH. Donor blood should also be treated with respect even though negative for HBsAg by sensitive tests.

\section{The acquired immunadeficiency syndrame (AIDS)}

Aids is caused by a retrovirus (HIV types 1 or 2). In Nonh America type 1 is predominant whilc both types 1 and 2 have been described in Africa. ${ }^{39}$ The first reported case of AIDS caused by HIV-2 in the U.S.A. was diagnosed in December $1987 .{ }^{39}$ The patient was a recent visitor from West A frica, where HIV-2 was originally described. No further evidence of its presence has been found in the U.S.A. in spite of extensive testing of blood samples. Modes of transmission are the same as those of HIV', and the same preventive methods have been recommended.

HIV is a retrovirus which preferentially infects $T 4$ lymphocytes, resulting eventually in their destruction. ${ }^{40}$ This markedly interferes with the efficiency of the immune system, and results in extreme susceptibility to develop opportunistic infections, for example, pneumocystis carinii pneumonia, and unusual cancers such as Kuposi's Sarcoma. HIV can also attack macrophages and cells within the central nervous system, sometimes leading to neuropsychiatric dysfunction with dementia. The epidemiology of this condition following a long incubation period of six months to six years is shown in Figure 4.

Most authorities believe that persons who develop AIDS are those with the more severe manifestations of infection with HIV. Some persons infected with HIV may remain apparently healthy and asymptomatic. Others may develop AlDS-related illnesses that may include such non-specific symptoms as fever, night sweats, weight loss, diarrhoea, tiredness or persistent lymphadenopathy, neurological symptoms, or non-life-threatening infections, e.g., oropharyngeal candidiasis. ${ }^{4}$

Anyone who has been infected with HIV is potentially infectious, since this virus has been isolated from the lymphocytes of asymptomatic individuals. It is therefore important to realize that any surgical patient may be unknowingly infected with HIV and so be potentially infectious.

Sensitive enzyme linked immunosorbent assays (ELISA) have been developed for establishing a diagnosis of HIV infection by measuring antibody to HIV. If the ELISA test is reproducibly positive it is confirmed by the more specific Western blot or immunofluorescent test. A small proportion of HIV infected persons may be seronegative. This may be due to an inability to produce HIV antibodies, failure to continue to produce them, or that infection has been too recent for development of antibodies.

HIV has been isolated from blood, semen, genital secretions, saliva, tears, urine and breast milk. Transmission by saliva, tears or urine has never been dacumented. HIV transmission is similar to that of Hepatitis $\mathbf{B}$ virus, namely parenteral, sexual and perinatal. The risk of acquiring HIV infection by occupational exposure is much less than that of acquiring HBV infection.

Needlestick or puncture by a sharp instrument or an eye splash with contaminated blood or body fluids from an HIV infected person, represents the only documented occupational risk of HIV transmission to the health care worker. In the study of 120 health care workers described by the CDC in Ottawa, ${ }^{18}$ needlestick injuries accounted for 57 of 94 ( 61 per cent) parenteral or mucous membrane exposures. Other types of exposures included splashing of blood or body fluid in the eye ( 13 per cent), open wound contamination (20 per cent) and scalpel wound (six per cent). No seroconversions to HIV antibody had occurred in any of the individuals. This observation is similar to that of the National Surveillance Program in the U.S.A. ${ }^{42}$ in which it was estimated that 40 per cent of 938 exposures were preventable. Again, no seroconversions to HIV antibody occurred, up to the time of reporting. It was thought that 26 per cent of the accidents could have been prevented by adherence to recommend barrier precautions. ${ }^{\text {' }}$ 
HIV is inactivated by exposure to:

1 Two per cent final concentration of active glutaraldehyde solution for 30 minutes (Sporicidin).

2 Two per cent final concentration of ordinary glutaraldehyde for ten hours (Cidex).

30.5 per cent sodium hypochlorite (bleach) for 20 minutes.

With a known case of HIV infection in the operating room, all the usual barrier methods must be used. Recommendations made by the CDC should be noted.'

\section{Cytomegalovirus (CMV)}

CMV is now recognized as being an important pathogen in all age groups. In addition to inducing severe birth defects, CMV may cause a wide spectrum of disease in older children and adults, ranging from an asymptomatic subclinical infection to a mononucleosis syndrome in healthy individuals to disseminated disease in the immunocompromised. ${ }^{43}$

CMV has a worldwide distribution. Approximately one per cent of newborns in U.S.A. are infected with this virus. The virus may be present in milk, saliva, faeces, semen and urine. CMV antibody titres are very high in almost 100 per cent of female prostitutes and homosexuals. Transfusion of whole blood or certain blood products may also transmit CMV with a frequency of two to ten per cent per unit transfused. Once infected, an individual probably carries the virus for life. Most commonly these infections remain latent, unless the individual becomes immunocompromised. Hepatitis with moderately elevated ALT may occur. Diagnosis cannot be made reliably on clinical grounds alone. Virus isolation from clinical specimens (urine, blood) or a four-fold rise in antibody titre is diagnostic. Repeat samples may be required.

\section{Epstein-Barr virus (EBV)}

This is a $B$ lymphotrophic human herpes virus which is worldwide in distribution and 25 to 70 per cent of adults who undergo a primary EBV infection develop the clinical syndrome of infectious mononucleosis (fever, lymphadenopathy and pharyngitis). EBV is transmitted primarily in saliva, but infections can also be passed on sexually or by blood transfusion. ${ }^{44}$ By adulthood, most individuals are EBV seropositive. Diagnosis is usually made on history, the presence of atypical lymphocytosis, heterophile antibodies, and EBV serology (seroconversion of viral capsid antibodics (VCA) or presence of elevated titres to early antibody (EA)).

\section{Herpes simplex virus}

Herpes Simplex virus (HSV.1, HSV-2) produce a variety of infections involving mucocutaneous surfaces, the central nervous system, and occasionally visceral organs, especially in immunosuppressed patients. The advent of effective antiviral chemotherapy for HSV infections has made prompt diagnosis of these syndromes of clinical importance. $^{45}$

HSV infection of certain cells (neurons in particular) may result in latency. Reactivation of the virus may occur resulting in rapid replication and the redevelopment of herpetic lesions. Ultraviolet light, immunosuppression and skin trauma are associated with reactivation.

HSV infections are found worldwide. Serological studies performed in the 1940's and 1950's demonstrated that in almost all populations studied, over 90 per cent of persons had antibodies to HSV by the fourth decade. More recent surveys in the U.S.A. indicate only 40 per cent of persons between 25 and 29 possessed antibodies to HSV with antibody prevalence increasing by about 1.5 per cent per year. ${ }^{45}$

Contact with active ulcerative lesions can result in transmission. Asymptomatic salivary excretions of HSV-1 has been reported in two to nine per cent of adults and five to eight per cent of children.

A diagnosis may be made clinically when characteristic multiple vesicular lesions on an erythematous base are present. This can be conlirmed by isolation of the virus in tissue culture, detection of antigen or by EIA, virus by electron microscopy or inclusions by light microscopy.

Mucocutaneous and visceral HSV infections are amenable to treatment with antiviral chemotherapy. Acyclovir has been the mainstay of therapy, but other antiviral drugs have also been introduced. ${ }^{46}$

\section{Respiratory infections}

These include bacterial and viral infections which are spread by droplets. Table IV indicates the common infections which may be encountered. The disease may be present during the incubation period when the patient is being anaesthetised. If anaesthesia is required, the anaesthetist should be careful to avoid the patient coughing in his/her face. The patient should wear a mask if there is evidence of infection. Chronic respiratory conditions such as tuberculosis are also spread by droplets and if diagnosed preoperatively, the anaesthetist should use the usual barrier methods to avoid direct contact with the patient's body fluid. One should be aware that tracheal, bronchial or lung washings of patients with AIDS may contain infectious organisms such as Pneumoncystis carnii. ${ }^{47}$

\section{Gastroenteric infectionts}

Infections of the gastroenteric tract can be a particular problem in patients with AIDS. The protozoa Crytosporidium and Isospora, although not particularly invasive, are persistent. ${ }^{48}$ They are easily diagnosed by standard methods, by the presence of oocysts in stool 
and can be successfully treated with Trimethoprin or Metranidazole. Heavy candida growth may be a particular problem in the upper GI tract of AIDS patients.

Immunocompetent patients with GI infections may demonstrate bacterial and viral organisms in faeces us shown in Table IV.

\section{Central nervous system infections}

Cerebrospinal fluid from AIDS patients may carry infectious organisms ${ }^{49}$ especially Toxoplasma, Cryptococcus and HIV. Care should be taken in handling these specimen as mentioned above.

\section{Summary}

The methods of dealing with various items of anaesthetic equipment in order to assure a fresh supply for each patient have been discussed. These consist of using disposable items, steam sterilization, disinfection by both chemical methods and pasteurization and the use of ethylene oxide sterilization.

The use of disposable bacterial and viral filtres to protect ventilators and soda lime cannisters is discussed. These can then be sterilized by ethylene oxide at less frequent intervals, i.e., weekly.

Protection of the anaesthetists' skin from contact with body fluids by the use of barrier methods are stressed. Methods to avoid penetration of the skin by needlestick and sharp objects are discussed. The increasing number of persons being treated for opportunistic infections makes it likely that anaesthetists will encounter increasing numbers of patients infected with HIV.

The more common infections encountered in the operating room in North America have been included, with methods of avoiding possible infection from them.

Constant vigilance and the use of universal precautions when caring for all patients is therefore required by the anaesthetist in the operating room in order to avoid contacting infection from patients.

\section{References}

I Recommendations for Prevention of HIV Transmission in Health Care Settings, Morbidity and Mortality Report, Centers for Disease Control 1987; 36, 25 ed., 629-33.

2 Handsfield HH, Cummings MJ, Swenson PD. Prevalence of antibody of human immunodeficiency virus and Hepatitis B surface antigen in blood samples submitted to a hospital laboratory. JAMA 1987; 258: 3395-7.

3 Dorsch JA, Dorsch SE. Understanding Anaesthesia Equipment. 2nd ed. Baltimore: Williams \& Wilkins, 1984; 417-22.

4 Methods of Prevention and Control of Nosocomial Infections: Recommendations for the Decontamination and
Maintenance of Inhalation Therapy Equipment, Nosocornial Infections Study Quarterly Report, Third Quarter, 1972, Centers for Disease Control 1973; 12-7.

5 Nelson EJ, Ryan KJ. A new use for pasteurization: disinfection of inhalation therapy equipment. Respiratory Care $1971 ; 16: 97-103$

6 Ping FC, Oulton JL, Smith JA, Skidmore AG, Jenkins $L C$. Bacterial filters - are they necessary on anaesthetic machines? Can Anaesth Soc J 1979; 26: 415-9.

7 Craven $D E$. Contaminated condensate in mechanical ventilator circuits. Am Rev Respir Dis 1984; 129 625-8.

B Ball PR. Viral removal cfficiency of the pall ultipor breathing system filter. Pall Technical Report BM 2115a (1987).

9 Bacterial Filtration Efficiency and Viral Filtration Efficiency. Marquest Report Lab No. 52623 and Lab No. 13663 (1988).

10 Stenhowse JIT. Mechanisms of gas filtration in Process Engineering Technique Evaluation - Filtration ed Satte: Morgan-Grampiar, 1969

11 Dienstag $J L$, Wands JR, Koff RS. Harrison's Principles of Internal Medicine. 11 ed. MeGraw Hill, 1987, 1330.

12 Stephens $C E$, Aach $R D$, Hollinger $F B$ er al. Hepatitis virus antibody in blood donors and the occurrence of Non- $A$, Non-B Hepatitis in transfusion recipients: an analysis of the transfusion-transmitted viruses study. Ann Int Med 1984; 101: 733-8.

13 Koziol DE, Flolland PV, Alling DW et al. Antibody to Hepatitis B Core Antigen as a paradoxical Marter for Non-A, Non-B Hepatitis agents in donated blood. Ann Int Med 1986; 104: 488-95.

14 Derrick JR. AIDS and the safety and adequacy of the Canadian blood supply. Can Anaesth Soc J 1986; 33: $117-22$.

15 Gilmore A. Red Cross gets go-ahead for autologous blood service. Can Med Assoc J 1988; 138: 157-9.

16 Orkin FK, Orkin FH, Cooperman $L H$. Complications in Anesthesiology, 1983; Philadelphia, W.B. Saunders Co., 706-14.

17 Cobo JC, Harley DP. The eyes as a portal of entry for hepatitis and other infectious diseases. Surg Gynecol Obstet 1985; 161: 71.

18 National Surveillance Programme on Oceupational Exposure to the Human Immunodeficiency Virus Among Health Care Workers in Canada. Can Med Assoc J 1988; 138: 31-3.

19 Update: Acquired Immunodefieiency Syndrome and Human immunodeficiency virus infection among health care workers. Morbidity and Mortality Weekly Report, Centers for Disease Control, 1988; 37: 229-39

20 McEvoy $M$, Porter $K$, Mortimer $P$, Simmons $N$, Shemsen $D$. Prospective study of clinical, laboratory and ancil- 
lary staff with accidental exposure to blood or body fluids from patients infected with HIV. Br Mcd J 1987; 294: 1595-7.

21 Dienstag $I L$. Hepatitis A Vinıs: identification, characterization, and epidemiologic observations. Popper $\mathbf{H}$, Schaffner F. Progress in Liver Diseases. New York: Grune \& Stratton, $1979 ; 6: 343-70$.

22 Decker RH, Kosakowski SM, Vanderbili AS et al. Diagnosis of acute Hepatitis A by NAVAB-M, a direct radioimmunoassay for IgM Anti-HAY. Am I Clin Path 1981; 76: $140-7$.

23 Szmuness W, Sci D, Dienstag JR et at. Distribution of antibody to Hepatitis $A$ antigen in urban adult populations. N Engl J Med 1976; 295: 755-9.

24 Burrell CJ. Serological markers of Hepatitis B infection Clinics of Gastroenterology 1980; 9: 47-63.

25 Blumberg BS. Plcomorphisms of serum proteins and the development of isoprecipitins in transfused patients. Bull New York Acad Med 1964; 40: 377-86.

26 Cooper WC, Gershon RK, Sunt SC, Fresh JW. A clinicopathological follow-up in Taiwan of Hepatitis B. N Engl J Med 1966; 274: 585-95.

27 Carstens J, MacNab GM, Kew MC. Hepatitis B Yirus infection in Andesthetists. Br J Andesth 1977; 49: $887-9$.

28. Chernesky MA, Browne RA, Rond: $P$. Hepatitis B Antibody prevalence in anaesthetists. Can Anaesth $S o c \mathrm{~J}$ 1984; 31: $239-45$.

29 Hepatitis B Virus Vaccine Safety: Report of an Interagency Group. Morbidity and Mortality Weekly Report, Centers for Disease Control 1982; 31: No 34, September 3.

30 Hollinger FB. Troisi CL, Pepe PE. Anti-HBs Responses to vaccination with a humar. Hepatitis $B$ vaccine made by recombinant DNA technology in yeast. J Infect Dis 1986; 153: 156-9.

31 Rizzetto $M$. The delta agent. Hepatology 1984; 3; 729-37.

32 Rizzerro M, Gerin J. Purcell RH. Delta antigen: evidence for a wariant of Hepatitis B virus or a Non-A, Non-B Hepatitis agent? In: Polland M (Ed). Perspectives in Virolagy XI. New York: Allen R. Liss (1981) p 105

33 Raimondo G. Smedlie A, Gallo L, Baibo A, Ponzesto A. Rizzetto $M$. Multicentre study of prevalence of HBVassociated delta infcetion and iver disease in drug addicts. Lancet (1982) 1: 249-51.

34 Smedlic A, Farci $P$, Verme $G$ et al. Influence of delta infection on severity of Hepatits $B$. Lancet (1982) 2: 945-7.

35 Purcell RH, Gerin JL. In: Viral Hepatitis and Delta Infection. Verme G, Bonino F, Rizzerto M. Alan R Liss (Eds). New York 1983; p 105.
36 Feinstone SM, Kapinkian AZ, Purcell RH, Alier HJ, Holland $P V$. Transfusion associated hepatitis not due to viral Hepatitis Type A or B. N Engl J Med 1975; 292: 757-70.

37 Wong DC, Purcell RM, Sreenivasan MA et al. Epidemic and endemic hepatitis in India: evidence for a Non-A, Non-B Hepatitis virus etiology. Lancet 1980; 2: 876-81.

38 Koretz RL, Sione D, Gitnick $G L$. The long term course of Non-A, Non-B, post-transfusion Hepatitis. Gastroentemlogy 1980; 79: 893-8.

39 Centers for Disease Control, AIDS due to HIV-2 Infection - New Jersey Morbidity and Mortality Report 1988; 37 . 33-5.

40 Laurence $d$. The immune system in AIDS. Scientific American 1985; 253: 84-93.

41 Fauci AS, Maucher AM, Longo El et al. Acquired immune deficiency syndrome: epidemiologic, clinical, immunologic and therapeutic considerations. Ann Int Med 1984; 100: 92-106.

42 McCray $E$ and the Cooperative Needlestick Surveillance Group. Occupational risk of the acquired immunodeficiency syndrome Among Health Care Workers. N Engl J Med 1986; 314: 1127-32.

43 Hirsch MS. Harrison's Principles of Internal Medicine. 11 ed. McGraw Hill 1987; 699.

44 Schooley RT. Harrison's Principles of Internal Medicine. 11 ed. McGraw Hill 1987: 699.

45 Corey $L$, Spear $P$. Infections with herpes simplex viruses. N Engl J Med 1986; 314: 686-91, 749-57.

46 Strauss $S E$ et al. Herpes simplex virus infection: biology, treatment and prevention. Ann Int Med 1985; 103: 404-19.

47 Shepherd FA, Fanning MM, Duperval $R$ et al. A guide to the investigation and treatment of patients with AIDS and AIDS-related disorders. Can Med Assoc J 1986; 34: 999-1008.

48 Soave $R$, Johnson WD Jr. Cryptosporidion and Isospora belli infections. J Infect Dis 1988; 157: 225-9.

49 Elder $G A$, Sever $J L$. Neurologic disorders associated with AIDS retroviral infection. Rev infect Dis 1988; 10: 286-302. 